Marquette University

e-Publications@Marquette

Marketing Faculty Research and Publications

Marketing, Department of

$1-1-1979$

\title{
Social Marketing: Its Ethical Dimensions
}

Gene R. Laczniak

Marquette University, eugene.laczniak@marquette.edu

Robert F. Lusch

University of Oklahoma Norman Campus

Patrick E. Murphy

Marquette University

Published version. Journal of Marketing, Vol. 43, No. 2 (1979): 29-36. DOI. (C) 1979 American Marketing Association. Used with permission. 


\section{SOCIAL MARKETING: ITS ETHICAL DIMENSIONS}

$\mathrm{T}$ HE concept of "social marketing" has gained widespread recognition in the field of marketing. Social marketing is " the design, implementation and control of programs calculated to influence the acceptability of social ideas and involving considerations of product planning, pricing, communications, distribution and marketing research" (Kotler and Zaltman 1971). The use of such marketing techniques has been expanding in our society. For example, most persons are familiar with recent campaigns to "'market' political candidates and their platforms, conserve energy, and abstain from smoking. Many of these effortsencompassing various aspects of marketing - go beyond simple advertising. For instance, some "stop smoking" organizations sponsor informational seminars, distribute special products designed to alleviate the desire to smoke in those who want to quit smoking, and initiate publicity aimed at the general public regarding the disadvantages of smoking. There is substantial pressure within the discipline of marketing and among the general public to expand the application of modern marketing's tools and theories in the dissemination of social ideas (Lazer and Kelley 1973). Like any new

Gene R. Laczniak is Assistant Professor of Business at Marquette University, Milwaukee, WI. Robert F. Lusch is Associate Professor of Business at the University of Oklahoma, Norman, OK. Patrick E. Murphy is Assistant Professor of Business at Marquette. social development, this trend may have positive and negative societal effects.

On the plus side, examples abound which illustrate how marketing thinking has improved the saleability of useful social programs (Kotler 1975). However, on the negative side, it is quite possible that the widespread involvement of marketing professionals in the marketing of social ideas may raise severe ethical problems and further turn public opinion against marketers and the marketing field. While Kotler and Zaltman (1971) in their original article on social marketing mention there may be some resistance to the concept-because it is costly, adds to promotional noise in the environment, and could be considered manipulative-they never directly broach the ethical aspects of social marketing.

To pursue the path of increased marketing of social programs and ideas without anticipating possible ethical consequences would seem rather naive. Yet there has been little discussion of the ethical dimensions of social marketing in the literature to date. For this reason, the authors decided to poll a group of knowledgeable individuals who could help demarcate the likely ethical and societal ramifications of expanded social marketing. There are prominent individuals within the field of marketing, as well as outside of it, who feel that marketers have yet to deal completely with the ethical issues involved in the promotion of economic goods and services (Alderson 1964; Westing 1976; Boulding 
1972). Through the poll, the authors attempt to delineate some of the ethical problems engendered by the growing application of sophisticated marketing techniques to social ideas.

\section{The Research Method}

\section{The Survey Participants}

Using survey research the authors sampled four groups of individuals whom they perceived to be "expert" in assessing what the emerging ethical implications of social marketing might be. The groups were:

- Professors of Ethics-(A sample of 176 ethics educators from the current Directory of American Philosophers was randomly selected.) This group was chosen because of their familiarity with ethical theory.

- Members of the Society for the Psychological Study of Social Issues-a group mainly composed of social-psychology academics. (A random sample of 176 members was chosen.) This group was selected to participate because of their likely sensitivity to emerging social issues.

- Subscribers to the Journal of Economic History - an academic journal written primarily for educators in economic history. (A random sample of 176 subscribers was drawn.) This group was chosen because of their presumed long-range perspective concerning the dynamics of the economic system.

- Marketing Practitioners-members of the American Marketing Association employed as marketing professionals. (A sample of 176 was randomly selected from the current AMA Membership Roster.) This group was chosen because its members are representative of the marketing professionals who increasingly will be involved in social marketing.

\section{The Survey Instrument}

The survey packet consisted of a cover letter, an exhibit page defining social marketing and providing a variety of illustrations of the technique, and a four-page questionnaire (see Appendix). The questionnaire itself included:

- Ten statements dealing with the possible societal effects of social marketing to which the participants responded on a five-point scale registering their agreement or disagreement.

- A list of 15 possible areas in which social market- ing techniques may be applied. The respondents were asked to assess the ethical sensitivity of specific issues if these issues were "socially" marketed.

- An open-ended question soliciting the opinion of the respondents regarding possible ethical concerns stemming from expanded social marketing projects.

The survey packet in draft form was pretested at three universities with members of the respondent groups. The revised package was further pretested with 40 members of the designated sample groups.

\section{The Response Rate}

Forty percent of the ethics professors $(n=71), 40 \%$ of the social psychologists $(n=70), 45 \%$ of the economic historians $(n=80)$, and $50 \%$ of the marketing practitioners $(n=88)$ returned usable questionnaires. As expected, the 309 respondents were an educated group (62\% held doctorates, $86 \%$ had at least a master's degree). Forty-one percent of all the respondents had held an administrative position in business at some time in their career and $18 \%$ had held a government post at some point.

\section{Discussion and Results}

The major findings of the study can be summarized by the following three statements:

- Social marketing is a two-edged sword perceived to have major beneficial elements, but also containing the potential to cause significant ethical controversies.

- The accountability of social marketers will be a major societal concern, but the initiation at this time of professional licensing or governmental review of such activity is undesirable or premature.

- When judging social marketing from an ethical standpoint, it appears to be difficult to separate the ethics of applying marketing techniques to social ideas and programs from the ethics of the ideas themselves.

Also, a finding that relates to all three of the preceding statements is that marketing practitioners tend to see social marketing in a more favorable light than ethicians, economic historians, or social psychologists.

\section{Social Marketing: The Two-Edged Sword}

Proponents of social marketing have pointed out the value of applying systematic marketing thought to the 
TABLE 1

The Ethical Dimensions of Social Marketing*

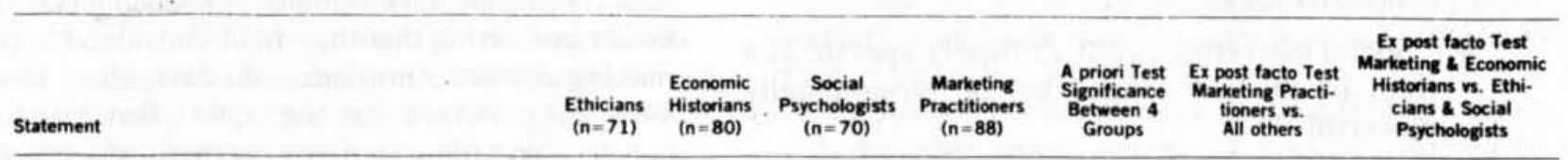

A. The utilization of marketing techniques with respect to social issues or ideas will help communicate these causes in a more effective manner.

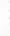

B. The application of marketing techniques to diffuse social issues and ideas is not a beneficial development.

C. The application of marketing techniques to diffuse social issues and ideas raises significant ethical questions.

D. The application of marketing techniques to social issues and ideas is a step toward a society wherein the opinions held by the population can be manipulated.

E. Marketers who assist others in diffusing social issues or ideas should be held strictly accountable for their actions.

F. A professional certification board which would "license" marketers (much like the American Bar Association certifies attorneys) should be formulated to control marketers working to diffuse social issues or ideas.

G. Marketers working to diffuse social issues or ideas should be regulated by a new government review board.

$\mathbf{H}$. When judging the application of marketing techniques to social programs or ideas in terms of their ethical appropriateness, one cannot separate the techniques from the ideas themselves.

001

.001

not tested

$\begin{array}{llllll}3.4 & 3.0 & 2.5 & 2.0 & .001 & .001\end{array}$

$\begin{array}{lllllll}4.8 & 4.4 & 4.5 & 3.8 & .001 & .001 & .01\end{array}$

$\begin{array}{lllll}4.1 & 4.0 & 3.7 & .001 & .001\end{array}$

$\begin{array}{lllllll}4.7 & 4.5 & 4.6 & 4.2 & .005 & .005 & \text { not tested }\end{array}$

$\begin{array}{lllllll}2.9 & 1.6 & 3.3 & 2.0 & .001 & \text { not tested } & .001 \\ 2.5 & 1.4 & 2.5 & 1.3 & .001 & \text { not tested } & .001 \\ 4.1 & 3.4 & 3.8 & 2.3 & .001 & .001 & \text { not tested }\end{array}$

*Numbers in table are median responses to a five point scale with (1)=strongly disagree, (2)=moderately disagree, $(3)=$ neither agree nor disagree, $(4)=$ moderately agree, and $(5)=$ strongly agree. Significance level is for a one-way Kruskal-Wallis analysis of variance.

dissemination of social ideas. An example would be the marketing of a major city's police department. Many say there is a need for such efforts because police departments are faced with a lack of public trust and increasing disrespect. Consequently, marketing activities are being used to find the roots of such distrust, to publicize the many benefits provided by the police, to recruit dynamic young police officers, to survey the public regarding their perceptions of the role of the policeman in the community, and to represent the view of the department on various matters by sending police officers to community forums.

The benefits of such applications were recognized by the respondent groups, as indicated by their general agreement with the statement "the utilization of marketing techniques with respect to social issues or ideas will help communicate causes in a more effective manner" (see Table 1, Statement A). Clearly, therefore, a perceived positive value exists in the emergence of social marketing.

However, another side of the social marketing issue began to appear with responses to subsequent statements. Except for the marketing practitioners, who on the average disagreed with the statement that social marketing would not be a beneficial development, the respondents were uncertain about the virtues of social marketing (see Table 1, Statement B). Several survey participants issued strong warnings such as the following:

- "Although ideas may be communicated more effectively with social marketing, those who have the dollars and power to use marketing 
techniques may communicate nonsociallybeneficial ideas."

- "Social marketing could ultimately operate as a form of thought control by the economically powerful."

Furthermore, the responding ethicians, economic historians, social psychologists, and, to a lesser extent, marketing professionals generally agreed that "the application of marketing techniques to diffuse social issues and ideas raises significant ethical questions" (see Table 1, Statement C). Numerous respondents questioned the propriety of marketing professionals making themselves available to improve and refine the salability of social issues when this service was based largely on the ability of the sponsor to pay for it. As one philosophy academic put it: "The basic problemethically-is the problem of power. For example, it might be $\mathrm{OK}$ for the Pentagon to use marketing campaigns to recruit personnel and attempt to shape the public's attitudes regarding the size of the defense budget if groups opposed to these measures have equal access to marketing capability. The question is: What will marketers do to assure that legitimate, impoverished minorities have equal access to marketing expertise?"

Further credence was lent to the viewpoint that the increased social marketing could have dysfunctional ramifications when all four respondent groupsethicians, social psychologists, economic historians, and marketers-generally agreed with the statement: "the application of marketing techniques to social issues and ideas is a step toward a society wherein the opinions held by the population can be manipulated." Ethics professors illustrated the greatest agreement with this position-as reflected by a median of 4.2 (see Table 1, Statement D). Social psychologists (median = 4.0) and economic historians (median $=4.1$ ) trailed only slightly in their level of agreement. In contrast, a smaller percentage of the marketing sample agreed with the statement, but they still demonstrated a substantial level of concern.

The question of the manipulation of social opinion through the use of propaganda is, of course, an old saw. It is not unique to marketers. Any group which is well represented in the decision making structure of a social system-physicians, attorneys, newspaper editors, etc.-has the leverage to abuse power. The issue of inordinate influence on the population by the mass media and other elements of the power elite has been and will likely continue to be a major topic of debate. The new consideration as far as marketers are concerned, is how the involvement of professional marketers in social marketing activities will affect the pub- lic's perception of the field of marketing. In essence, by undertaking the development of social marketing, marketers are saying that they hold considerable power in making certain communication campaigns successful. This may indeed be the case. But considerable power-according to many normativist writers-must be balanced by corresponding responsibility (Davis 1967; Davis and Blomstrom 1975). Therefore, marketing professionals involved in social marketing should understand what the ethical and social consequences of their social campaigns will be. The results of this survey suggest there may be multiple issues of this variety to ponder.

It should be added, however, that careful analysis of Table 1, (Statements A-D) reveals that marketing practitioners tend to view social marketing in a much more favorable light than ethicians, economic historians, or social psychologists. When this ex post finding was tested using the Kruskal-Wallis test for statistical significance, strong support was found for the notion that marketers did see things differently. In short, marketing practitioners viewed social marketing as more useful, beneficial, and less likely to raise significant ethical issues or problems of manipulation. If the sample of marketing professionals polled here is typical of those who will be engaged in implementing social marketing programs (or in defending them in the political arena), they must recognize that their views are not shared by important opinion leadership groups that influence public thought.

\section{The Control of Social Marketing}

Judging from the aggregate responses of the survey participants, the growth of social marketing could be a Pandora's Box. While social marketing is curious and fascinating in its potential to improve effective mass communication, the hasty "opening of the box"-a wholesale application of social marketing - could release ethical and social problems of large dimensions. For example, is it in the best interest of society for politicians increasingly to rely on individuals skilled in advertising and marketing to tailor their campaigns? Is it proper that marketing research methods are used to determine which issues appeal to various constituencies and how these often conflicting views can be optimally incorporated into the party platform without alienating many voters? Is it beneficial that image studies shape the candidates external appearance?-that copywriters and public relations people stage appealing TV speeches and appearances for the candidates?-that politicians are sold like soap? Perhaps. But such issues need to be analyzed carefully.

Traditionally, professionals have guarded against ethical and social abuses in three ways. Self regulation 
has always been present to a degree and represents the control the individual's own value system exerts upon his or her actions. Professional or industry regulation, a second mode, embodies the value norms held collectively by a membership operating in a given field. Such norms are often reflected in codes of ethics or statements of principles held by an industry or professional association. Sometimes, the framework of professional regulation (although not always exercised) is especially rigorous. For instance, in the field of law, it is accepted that attorneys must be licensed to certify their suitability to practice. Legal or ethical abuses by them can result in their being "disbarred"-losing certification-although this outcome is relatively rare. Government regulation is the third and most potent form of control. Generally, the law is utilized to set the lowest common denominator of acceptable professional standards and behavior.

The responses of the groups surveyed in this study indicate a clear feeling that the actions of social marketers should be controlled in some way. The vast majority of respondents agreed that "marketers who assist others in diffusing social issues or ideas should be held strictly accountable for their actions" (see Table 1, Statement E). However, it is important to note that marketing practitioners were not as harsh in their responses as reflected in the fact that they were less likely to agree (by a statistically significant amount) that marketers should be held strictly accountable for their actions.

For the most part, however, the various groups polled were not in favor of either professional or government regulation (see Table 1 , Statement F, G). The perceived experts were generally unsupportive of the proposition that "A professional certification board which would license marketers should be established to control marketers working to diffuse social issues or ideas." Only the social psychologists in the sample indicated mild support for this option (see Table 1, Statement F). Furthermore, the economic historians sided with the marketing practitioners and were generally opposed to certification. On an ex post facto basis (see Table 1, Statement F) it was found that the ethicians and social psychologists were significantly more in favor of certification than the economic historians and marketing practitioners.

The groups clearly rejected the government alternative when a majority of the respondents, moderately or strongly, disagreed with the proposition that "marketers working to diffuse social issues or ideas should be regulated by a government review board." Comments such as "Why should government regulate free speech?" and "The last thing we need is more bureaucracy!" were common (see Table 1, Statement G).
Once again, however, an ex post facto analysis revealed that the economic historians and marketing prac titioners were much more strongly opposed to government regulation of social marketing.

In summary, then, marketing practitioners agree with the other groups that social marketers should be held accountable. However, they are much more willing to leave the matter to the marketer's own sense of ethics. This view is shared by economic historians, another group traditionally opposed to external controls. Importantly, if marketers prefer internal controls, they should probably impose tighter standards than they ideally prefer since outsiders appear to be more critical of the ramifications of social marketing than marketers themselves.

\section{Are Social Marketing Techniques Ethically Neutral?}

Apologists for expanded social marketing argue - and perhaps rightly - that social marketing techniques are merely tools which, when used properly, can aid effective communication or when misused, can compound social abuse. According to this view, marketers are no more at fault than the owner of a sporting goods store when one of his customers uses a recently purchased baseball bat in an assault.

Critics take a slightly different view. They maintain that professional marketers must assume partial responsibility for the impact of any social program or idea which has been professionally marketed. Most often, critics picture the marketer as responsible for subsequent actions just as the gun shop owner who illegally sells a handgun to a minor would be responsible. Probably, the truth about social marketing lies somewhere between these extremes.

The essential difference between the two viewpoints, however, lies in the degree to which the propriety of applying marketing techniques to social issues and the ethical dimensions of the social ideas themselves can be separated. If society generally agrees that such a separation (distinction) is possible, marketers will be perceived as relatively blameless if abuses occur. If society cannot distinguish between the propriety of social marketing methods and the ideas being marketed, marketing professionals will be held partially responsible when programs they have promoted cause social problems. For example, the Indian government, during Indira Gandhi's administration, sponsored systematic communications campaigns to promote family planning. Since this idea was not popular with the public, those helping disseminate the concept, as well as the sponsors, were held in some contempt.

The experts polled in this study were asked to comment on the possibility of making the distinction between the propriety of the idea and the notion of market- 
ing it. The majority of the respondents seemed to agree that one cannot separate the marketing techniques used from the idea itself in judging the "ethical appropriateness" of a marketing campaign which has helped diffuse a social idea (see Table 1, Statement H). This suggests that controversial and ethically "charged" topics such as pornographic entertainment, abortion, and political platforms, if they are promoted with full scale marketing campaigns, will create some ill will for the discipline of marketing.

It should be added, however, that the marketing practitioners in the sample disagreed, on the average, that the ethical appropriateness of marketing techniques and the idea being marketed could not be separated (see Table 1, Statement H). The level of disagreement was significantly different from the other three groups based upon the ex post facto analysis. Perhaps marketers believed they could separate the ethical dimensions of marketing techniques from the ideas being marketed because marketers have something to gain if social marketing continues to grow in popularity. Expanded social marketing would provide income for marketing professionals, jobs for marketing graduates, and additional issues to ponder for marketing educators. Yet, as this survey suggests, there is reason to be wary of its widespread use.

\section{Implications and Conclusion}

The survey findings seem to hold several implications for marketing practitioners.

- As social marketing efforts increase, large segments of the public may not distinguish between controversial topics being marketed and the tools used to promote them. This could lead to marketers being perceived as the "neopropagandists" of our society-hardly a positive public badge for the discipline of marketing to wear.

- Social marketing may have many ethically controversial dimensions as the findings of this survey suggest. If the public shares the view of the participants in this study, one can speculate that there likely will be some pressure to control social marketing efforts. While the expert samples polled in this survey have no desire-at this point-to license or legally regulate social marketing, such public pressure could quickly materialize.

- Marketing practitioners have a responsibility to carefully consider the ramifications of their social marketing campaigns. One possible secondary consequence of ill-conceived and later criticized campaigns might be the development of an attitude among bright, young students that the field of marketing is not a worthwhile area of study. Perhaps opinion leaders in the areas where social marketing will be operating (public safety, politics, entertainment, etc.) should be consulted prior to launching the marketing campaign in order to better gauge ethical ramifications. Such actions may forestall damaging criticism. Marketing academics should likewise address the influence of expanded social marketing on society, the economic system, and the discipline of marketing.

- Since the data indicate the "outsiders" are more critical of social marketing than marketing practitioners, special attention must be given to the analysis of public opinion regarding this topic.

- By venturing into the wholesale development of social marketing, marketing professionals may acquire considerable social power without prudently assessing the resulting responsibility that they necessarily must bear.

In conclusion, the results of this survey should not be interpreted as a wholesale condemnation of efforts to broaden the application of marketing methods and thinking. It seems obvious that marketing has a beneficial role to play in the dissemination of social ideas relating to areas such as health care, the performing arts, mass transportation, and environmental improvement. The thesis that the widespread use of social marketing could have substantial, ethical ramifications should be viewed from a realistic perspective. Society could deport every marketing academician and practitioner, burn all the textbooks and manuals, and forbid the involvement of any marketing professional in the social arena and most of the ethical dilemmas regarding propaganda, social control, etc. would still remain. Such delicate, ethical responsibilities are not unique to marketing but are shared by other academic areas (e.g. . social psychologists who assist attorneys in jury selection by creating psychological profiles). In fact, most social science practitioners need to do some ethical "soul searching."

This limited-scope study does present some initial evidence which intimates that marketers ought to confront the ethical issues associated with social marketing. However, the opinions of the experts polled here cannot be generalized to the total public because (a) their responses on the topic may have been partly influenced by the description of social marketing provided to them (again, see Appendix); (b) they may have conjured in their minds the worst possible abuses of social marketing as they filled out the questionnaire; and (c) individuals in these groups, due to their educa- 
tion and professional positions, are probably more sensitive to the potential abuse of the techniques. Despite these qualifications, it does seem clear that a further examination of the ethical aspects of social marketing would be in the best interest of marketing professionals.

In the immediate future, a number of related research questions need to be asked and answered by persons concerned with the theory and practice of social marketing.

- Is the increased involvement of marketing specialists in the promotion of ideas, personalities, and organizations a beneficial development from the standpoint of U.S. society?

- What specific segments of the public benefit the most? Who loses? How can such social costs and benefits be operationally defined?

- To what social causes or ideas might social marketing offer the most immediate societal benefits?

- What are some of the specific ethical questions facing social marketers today?

- What constitutes a "good"' (or bad) product or idea? What constitutes a "good" (or bad) marketing practice? What is the responsibility of the firm to consider such issues?

- Does individual responsibility sometimes exceed the responsibility vested in the firm?

- What is "different" conceptually and practically about social as opposed to traditional marketing?

- Do social critics primarily "object" to certain marketing techniques or is it the idea/ organization/person being marketed that is the source of objection?

- Can social marketers avoid making distinct value statements and still conduct effective campaigns?

- Can members of the general public distinguish between ethical marketing practices as opposed to the ethical implications of the social product being marketed?

- How can possible abuse of social marketing be prevented or controlled?

Marketers need to initiate and explore an empirical tradition in coming to grips with these questions (Beauchamp 1975; Mappes and Zembarty 1977; Walton 1977). Too many "sermons," though well intentioned, have already been delivered. Methodologies such as the construction of scenarios to gauge hypothetical executive, consumer, and citizen reactions and the gathering of oral histories from past and present decision makers regarding ethical dilemmas, would seem to offer promising avenues. In addition, more rigorous methodologies also offer promise. The use of conjoint analysis to determine what aspects of a social marketing program people reject and/or view with favor is a possibility. Perhaps cluster analysis could be used to segment the public based upon their attitudes, opinions, and ethical evaluations of various social goods. Fruitful approaches to this important topic are only bounded by the researcher's lack of imagination. In short, once the proper research questions are settled in the marketing of social concepts, then a host of quantitative and qualitative methodologies can be applied to their solution in the same fashion they have been productively applied to the marketing of traditional economic goods. Finally, unless the potential ethical dimensions of social marketing are faced squarely, the obvious societal benefits of social marketing may never be completely realized.

\section{Appendix}

\section{Concept Description of Social Marketing}

Businessmen typically define the term marketing as the planning, pricing, promotion, distribution, and servicing of goods desired by consumers. As a general rule, marketing has been associated with the economic exchange of goods. Marketing has, therefore, usually been perceived as a business function engaged in by business firms to distribute and/or sell their physical products to the general public and to learn about the kind of products and services the public would like. Almost everyone is familiar with at least the results of marketing decisions. For example, partially because of marketing analysis:

McDonald's created and promoted the "Quarter Pounder' for hearty appetites;

Texas Instruments and other major producers of pocket calculators were able to investigate customer preferences for calculator features and generate the customer volume which permitted substantial price reductions;

Chevrolet has recently introduced a "Bison" heavy duty, conventional-style, long distance truck to expand its existing line of motor trucks and make its dealerships more competitive with this segment of the industry;

Maytag, Whirlpool, and other major appliance manufacturers were able to publicize their warranties and product service and thereby widen the national distribution of their products. 
These examples are merely illustrations of marketing in its traditional context.

Today, many marketing experts are suggesting that the role of marketing can be much broader than purely economic exchange and could also logically encompass exchanges dealing with social issues and ideas. For example, an individual participating in an election exchanges his vote for the promise of the attempted enactment of a particular political platform if his candidate is elected. Thus, this situation involves exchange. Proponents of this new view of marketing argue that the realm of marketing includes the facilitating of social exchanges as well as goods and services. One set of authors defines social marketing as "the design, implementation, and control of programs calculated to influence the acceptability of social ideas and involving considerations of product planning, pricing, communication, distribution and marketing research." Thus, the tools and theories of modern marketing could be extended so that marketing can be used in the following situations:

To Market Political Campaigns. An example would be the marketing of a political candidate. Marketing research methods could be used to determine which issues appeal to various constituencies; image studies could help shape the candidate's external appearance; copywriters and public relations men could help stage appealing TV speeches and appearances.

To Market Community Programs. An example would be the marketing of a police department in a major city. There is a need for such efforts because many police departments are faced with a lack of public trust and increasing disrespect. Consequently, marketing activities might be used to publicize the many benefits provided by the police, to recruit dynamic young police officers, to survey the public regarding their perceptions of the role of the policeman in the community, to provide police officers at community forums to represent the view of the department on various matters.

To Market Social Causes. An example would be the promotion of various social issues. Most everyone is familiar with advertising which advocates pollution control, family planning, or the abstention from smoking. Eventually marketing campaigns could be formulated which include all aspects of marketing strategy to help influence the dissemination of such ideas. For instance, a "stop smoking" organization might sponsor informational seminars and distribute special products designed to alleviate the desire to smoke as well as initiating publicity regarding the disadvantages of smoking.

The use of marketing in these broader contexts is in its early stages. However, supporters of social marketing suggest that more efforts need to be expended in preparing such campaigns and in teaching present and future marketing practitioners to develop social marketing strategies for these broader exchange situations.

\section{REFERENCES}

Alderson, Wroe (1964), "Ethics, Ideologies and Sanctions," Report of Committee on Ethical Standards and Professional Practices, Chicago: American Marketing Association, December, 1-20.

Beauchamp. Thomas L. (1975), ed., Ethics and Public Policy, Englewood Cliffs, NJ: Prentice-Hall, Inc.

Boulding, Kenneth (1972), “The Ethics of Persuasion," Chicago: American Marketing Association Conference Proceedings.

Davis, Keith (1967), “Understanding the Social Responsibility Puzzle: What Does Business Owe to Society?" Business Horizons, 10 (Winter), 45-50.

, and Robert L. Blomstrom (1975), Business and Sociery: Environment and Responsibility, 3rd edition, New York: McGraw Hill.

Kotler, Philip (1975), Marketing for Nonprofit Organizations, Englewood Cliffs, NJ: Prentice-Hall, Inc., Part V.

- and Gerald Zaltman (1971), "'Social Marketing: An Approach to Planned Social Change,"Journal of Marketing. 35 (July), 3-12.

Lazer, William and Eugene J. Kelley (1973), Social Marketing: Perspectives and Viewpoints. Homewood. IL: Richard D. Irwin, Inc., 10.

Mappes, Thomas A. and Jane S. Zembarty (1977), Social Ethics: Morality and Social Policy, New York: McGraw Hill.

Walton, Clarence (1977), ed.. The Ethics of Corporate Conduct. Englewood Cliffs, NJ: Prentice-Hall. Inc.

Westing, J. Howard (1967), "'Some Thoughts on the Nature of Ethics in Marketing," Chicago: American Marketing Association Proceedings, 161-163. 